\title{
Water resources management strategies for adaptation to climate induced impacts in South Africa
}

\author{
PIERRE MUKHEIBIR ${ }^{1}$
}

ENERGY RESEARCH CENTRE, UNIVERSITY OF CAPE TOWN

Published in Water Resources Management, 2007,

DOI : 10.1007/ s11269-007-9224-6

\begin{abstract}
:
This paper focuses on the development of a framework for strategy considerations for water resources management in South Africa to meet the development goals in the municipal and agricultural sectors. The north western part of South Africa experiences severe periods of drought and according to the climate change projections, will be most vulnerable to future climate induced water supply stress. A framework for selecting appropriate strategies is presented. A series of potential adaptation strategies most suitable for long term adaptation are discussed. These include both supply and demand side strategies. Barriers and obstacles to implementing these strategies include human and financial resource deficiencies at local municipal and community levels.
\end{abstract}

Key words: climate change, adaptation, water resources management, agriculture, South Africa (No of words: 5925)

\footnotetext{
' Pierre Mukheibir: Researcher and Project Manager at the Energy Research Centre, University of Cape Town Contact: Tel: +27 21 6502824, Email: pierre.mukheibir@uct.ac.za
} 


\section{Introduction}

South Africa's rainfall is already highly variable in spatial distribution and unpredictable, both within and between years (DEAT, 2004). Thus water is considered a limiting resource for development in this country and a change in water supply could have major implications for most sectors of the economy. Factors that contribute to vulnerability in water systems in South Africa include seasonal and inter-annual variations in rainfall, which are amplified by high runoff and evaporation rates.

In 2004, eleven of the nineteen Water Management Areas (WMAs) in the country were facing water deficits due to drought (Otieno FAO and Ochieng GMM, 2004). If the occurrence of drought became more frequent, the impact on water resources, and consequently agriculture, would be significant.

Climate change is expected to alter the present hydrological resources in Southern Africa and add pressure on the adaptability of future water resources. Taking note of the substantial uncertainties around rainfall projections, there is nonetheless a tendency for the majority of models to suggest a decrease in rainfall over the western part of southern Africa in coming decades. Coupled with warming, this implies net drying, with negative consequences on water supplies and agriculture (Fischer et al., 2002; IPCC, 2007).

Although climate change seems marginal compared to the pressing needs of poverty alleviation, health, hunger and economic development, it is becoming increasingly clear that the achievement of development goals, such as those related to food and water, can be seriously impeded by climate impacts. The collective opinion in recent literature on adaptation is that it is essential that the impacts of climate change be moderated in the poorer parts of the world, where levels of poverty will be exacerbated if hit by climate change. It is the countries with the fewest resources that are most likely to bear the largest burden of climate change in terms of loss of life, adverse effect on income and growth, and damage to general living standards, such as access to safe water, energy and shelter (Stern, 2006).

It is for this reason that the linkages between climate change and development are receiving more attention in political and scientific circles. Development can be planned in such a way that that development goals are achieved, while at the same time, vulnerability to climate change is reduced, facilitating a sustainable development that realises economic, social and environmental (local and global) benefits (Argrawala, 2005; Davidson et al., 2003; Markandya and Halsnaes, 2002; Munasinghe and Swart, 2005).

Climate change response strategies could therefore potentially act as significant factors in boosting sustainable economic and social development. Strategies that are designed to address climate variability and change and address the development objectives of the country are clearly in the national interest, especially if they include poverty alleviation and job creation.

This paper therefore sets out a methodology that could be applied at a national sector level. The impact of climate change on agriculture and municipal water supplies is assessed and viable strategies identified. The barriers to implementing these strategies and planning for climate impacts are presented.

\section{Methodology for long-term strategy development}

Following the process depicted in Figure 1, the initial step is to determine the physical vulnerability of water resources to climate impacts, In other words, the potential for water scarcity under climate variability and change. Existing documents and plans may exist to assist in the identification of the vulnerability. Some tools, such as scenarios planning, can help to evaluate future pathways of resource vulnerability. 


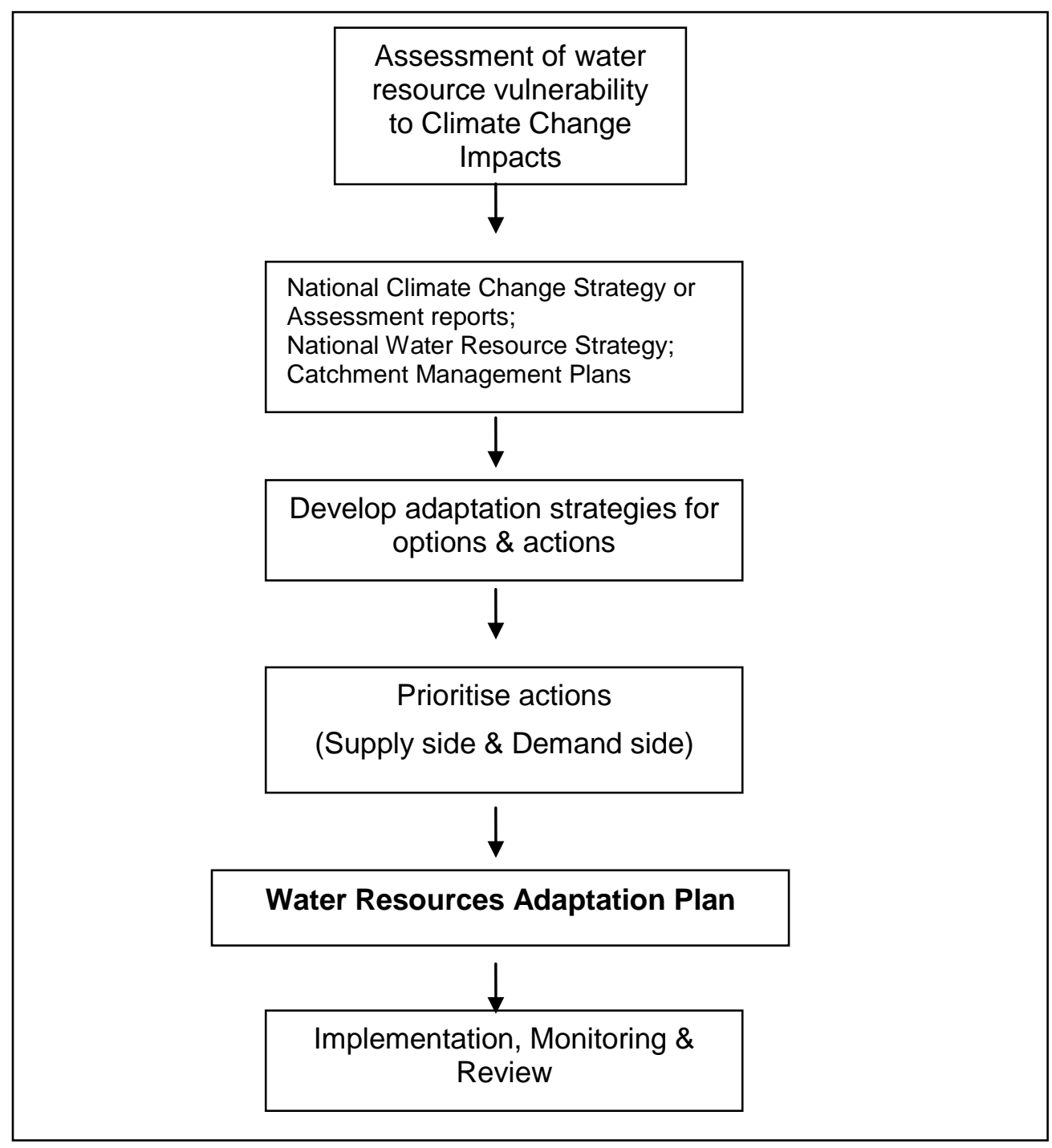

Figure 1: Framework for developing Water Resources Adaptation Plans

Once the key vulnerabilities are identified, it is necessary to formulate an adaptation strategy consisting of a range of adaptation actions. These adaptation actions need to be developed for the local context in conjunction with key stakeholders, experts in the sector and climate specialists who can comment on the nature of the climate variability. This is necessary in order to assess the secondary impacts of pursuing certain adaptation actions and to ensure there is equity and sustainability given the complex institutional arrangements of the sector.

A key challenge to water security is the reconciliation of water demand and supply both for the medium and long term. Short term responses to variability might be seen as coping strategies, whereas longer term actions that help to deal with climate change could be collectively called adaptation strategies. This is consistent with Callaway (2004) who suggests that there are more conceptual similarities than differences between the adjustments that are made to cope with climate variability and those made to adapt to climate change. The obvious similarity is that the aim of both types of actions is to avoid meteorologically induced damages when predicting them is subject to some error. Both actions have the potential to improve society, whilst making decisions under some risk, both involve reallocating scarce resources to make the adaptive adjustments. The major difference, according to Callaway, between variability and change is that historical records are more reliable for planning for variability than the reliability attached to climate prediction models. The variability in the existing climate is much easier to plan for than the variability associated with alternative climates.

By applying an initial filtering tool (as is illustrated in Figure 2) which is qualitative, the responses to climate variability can be evaluated for their long term suitability to ensuring resilience to future climate impacts, and also ensuring that the local development goals such as access and job creation are achieved. 


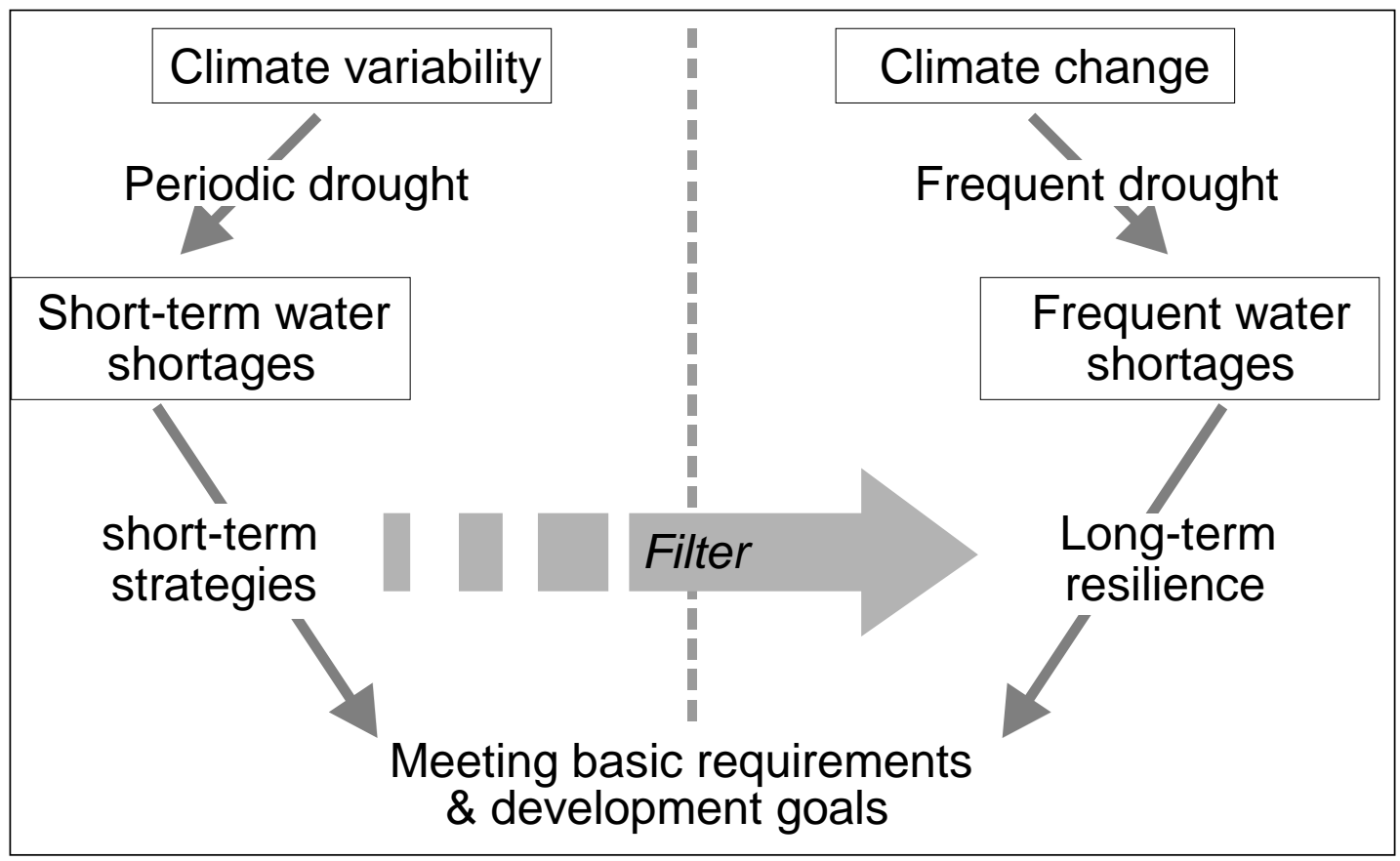

Figure 2: Diagrammatic view of the relationship between climate variability and climate change (Mukheibir, 2007)

Once key adaptation actions have been identified, they need to be prioritised. One method of evaluating which actions might be pursued first, is multi-criterion analysis (MCA). MCA enables options to be evaluated using a range of criterion that includes unquantifiable analysis, especially when distributional implications need to be considered. The purpose of using MCA is to aid decision-making rather than to evaluate options on monetary terms. It is useful for assessing options for adapting to climate change as there are many factors that need to be considered including equity, efficiency, short or long term benefits as well as many other non-monetary factors. Other tools such as cost-benefit analysis and social accounting matrices are useful when determining the financial implications of an intervention, both in terms of cost and benefit to society.

A key component of this climate change strategy framework is the ongoing monitoring of the programmes and the projects that are prioritised and implemented. The effectiveness of the interventions should be regularly assessed and modifications made if necessary. Adaptation to climate change is not an event, but rather it is an ongoing process of social learning. The development of the adaptation plan should lead to adaptation actions being integrated into development policy and planning at every level. Development itself is key to adaptation, since adaptation should be an extension of good development practice and should reduce vulnerability. All levels of government should ensure that policies, programmes, budget frameworks and projects take account of climate change, since critical economic, social and ecological challenges can only be effectively addressed on a regional scale. However, there is little evidence of this since low- and middle-income countries face two key barriers to integrating climate change into developing planning, viz. institutional constraints and technical capacity (Burton et al., 2002; Mukheibir, 2007; Stern, 2006).

The socio-economic vulnerability and adaptive capacity should be considered along side the physical aspects when developing holistic strategies to address potential water scarcity. Both small and large scale farmers have identified social, economic, political and environmental issues at all scales that expose their vulnerability during periods of climate stress. It is important therefore that these issues are included when assessing the vulnerability of farmers and when implementing plans for assistance and development, especially if such events increase in frequency and magnitude (Reid et al., 2005). However, this is not addressed in this paper and readers are directed to the works of Jeffrey \& Gearey (2006), Turton (1999) and Reid \& Vogel (2006).

\section{Background}

South Africa is generally viewed as a water-stressed country with an average annual rainfall of 500mm, which is approximately $60 \%$ of the world average. The greater part of the interior and western part of the country is arid or semi-arid. About $65 \%$ of the country receives less than $500 \mathrm{~mm}$ per year and $21 \%$ of the country receives less than $200 \mathrm{~mm}$ per year as is illustrated in Figure 3 (DWAF, 2004a).

Since rainfall displays strong seasonality, the natural availability of water across the country is variable, with stream flow in South African rivers is at a relatively low level for most of the year. Groundwater also has an important role to play in rural water supplies, but few major groundwater aquifers exist that can be utilised on a large scale due to high salinity in most parts of the country (DWAF, 1996). 


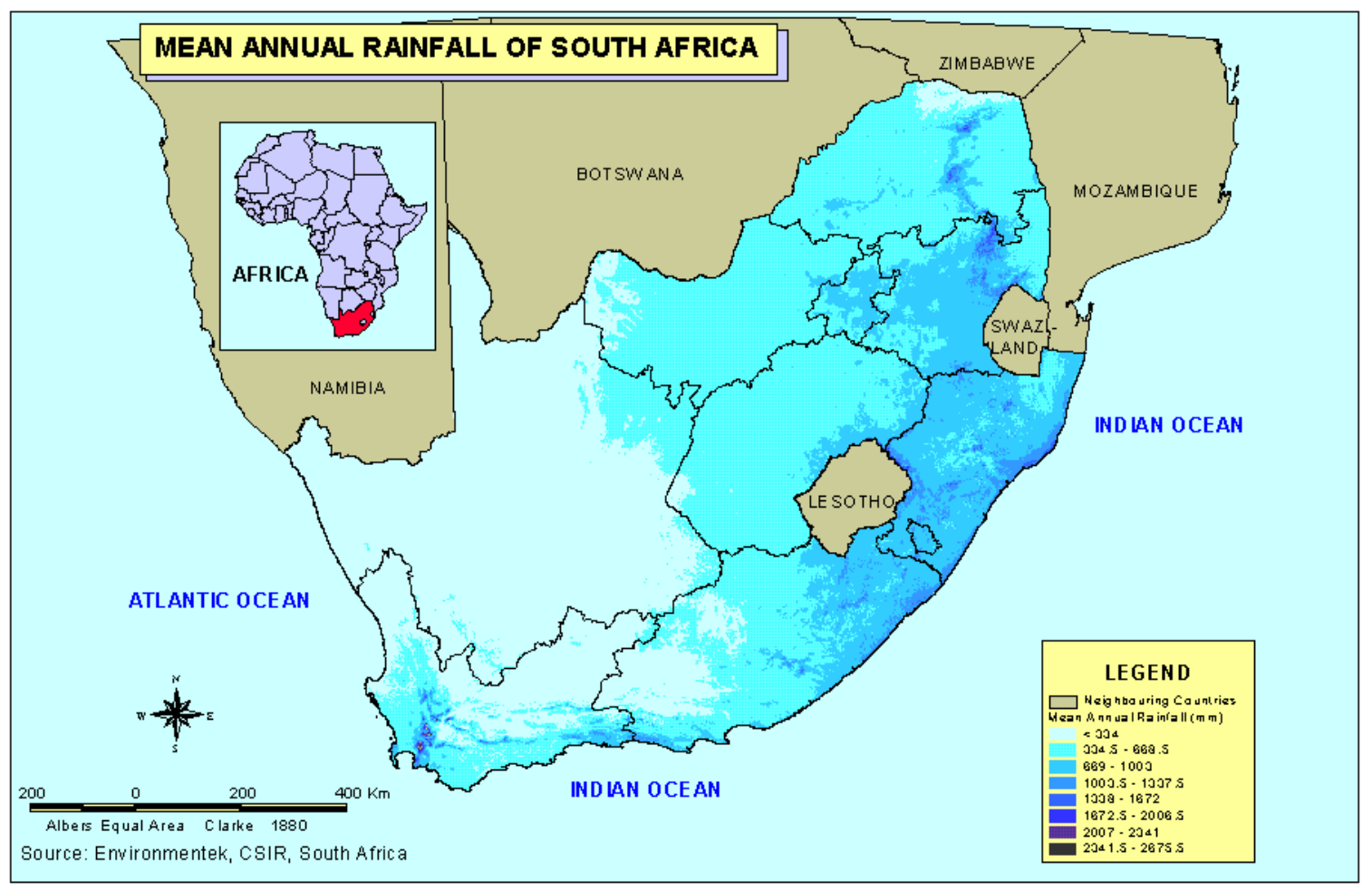

Figure 3: Rainfall map of South Africa

(Source: http://www.ngo.grida.no/soesa/nsoer/indicatr/m_rain.htm)

The total amount of water required for 2000 was estimated at $12871 \times 10^{6} \mathrm{~m}^{3}$, a figure close to the available limits. As is illustrated in Figure 4, agriculture is by far the largest user of water, using $62 \%$, while urban and rural domestic requirements make up $25 \%$ and $4 \%$ respectively. Agriculture and forestry together use two thirds of the available water resources (DWAF, 2004a).

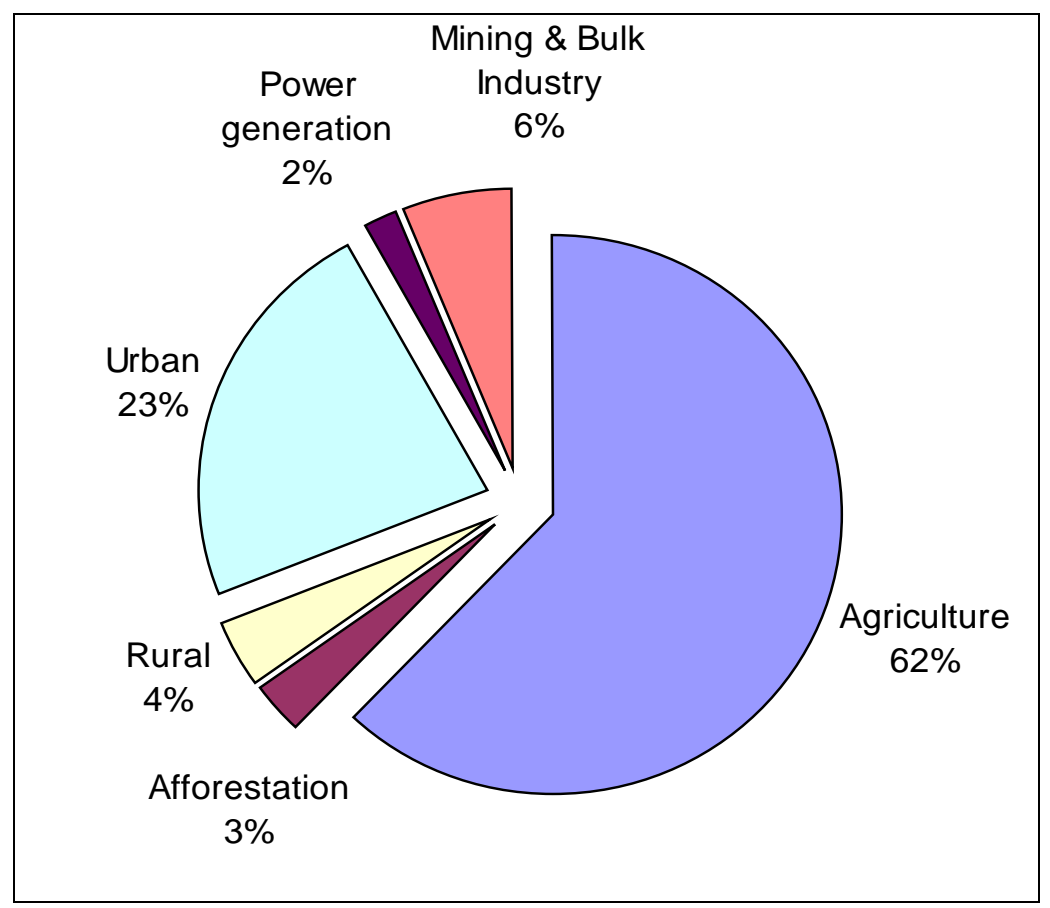

Figure 4: Water demand for 2000 per sector

(DWAF, 2004a) 
Three main issues affect South Africa's water resources management. Firstly, the natural conditions, low rainfall with high evaporation rates, which together create low availability of runoff. Climate variability makes it difficult to estimate the runoff. It is has been projected that climatic change will have notable impacts on the available run off. This is discussed further in section 4. Secondly, population growth and economic development lead to greater water demand and increased pollution of available resources. Thirdly, the policies pertaining to management of water resources determines the approach taken by relevant authorities to managing the resource and directly impacts other driving forces and pressures.

The legacy of apartheid has left the country with the huge task of providing sustainable water delivery services to its population in order to meet these basic needs. The majority of the people without basic domestic water services live in rural areas. According to the 2001 census, $84 \%$ of South Africans have access to piped water, in which $32 \%$ directly into their homes (SSA, 2003).

To address the needs of the rural poor, the Growth, Employment and Reconstruction (GEAR) strategy focuses on land reform and associated agricultural development and on the provision of infrastructure, notably water (DWAF, 1997). The two main objectives of GEAR are to attain both equity and economic growth. The combination of these objectives makes it clear that economic development progresses towards some set of social goals - notably more jobs and more equal income distribution. Without adequate supply of water for economic activities, these two objectives will be difficult to achieve. Basic adequate water services are defined by the Department of Water Affairs and Forestry (DWAF) (1994) as potable water supply of 25 litre/person/day within a walking distance of $200 \mathrm{~m}$. This is considered sufficient for cooking and drinking. To address the issue of affordability, the government has committed itself to providing 25 litres per day, free of charge (the life-line tariff), to be implemented by local authorities (Mosdell and Leatt, 2005). This level of free service however is still well below the World Health Organisation's (1995) recommended daily minimum of 50 litres per day.

DWAF (2004a) has released the National Water Resource Strategy (NWRS) to address the management of the water resources to meet the development goals of the country. One of the key objectives of the NWRS is to identify areas of the country where water resources are limited and constrain development as well as development opportunities where water resources are available.

Some unique features and development challenges left by the former homeland system in South Africa has resulted high rural density population areas, dislocated settlements and resettled communities which are isolated from economic opportunities. The level of interdependence of rural communities and distant large cities is high. On farms in the former so-called white rural areas poverty is also rife. Infrastructure is skewed in favour of commercial farming areas, and rural people generally do not have access to natural resources (RSA, 2000).

The social value of agriculture warrants special attention when deciding on competitive allocation of water among sectors since it contributes to food security and job creation. It is interesting to note that irrigated agriculture contributes only $1.5 \%$ to the GDP. Rain fed cultivation, livestock farming and afforestation contribute approximately $3 \%$. The secondary contribution to the economy through the provision of raw materials and demand for goods and services should however, not be ignored. It has been estimated that agriculture supports about $25 \%$ of the manufacturing sectors contribution to the gross domestic product (DWAF, 2004c).

There is a large potential for water saving in this sector given that between $30-40 \%$ of the irrigated water is lost through leaks and evaporation. Not all the water abstracted for irrigation by conventional methods reaches the roots systems of the plants. Conveyance losses due to the age of the schemes and leaking canals add to the losses. Irrigation methods, irrigation scheduling, soil type, soil penetration and crop selection all have significant impact on the efficient use of water in agriculture (DWAF, 2004c).

The changes in the South African agriculture have been shaped by substantial macroeconomic and social reforms as well as agricultural reforms, such as the deregulation of the marketing of agricultural products, removal of certain tax concessions favouring the sector, reduction of fiscal allocation to the sector, land reform and trade policy reforms. The withdrawal of most forms of support to commercial farmers has had the important effect of greater involvement in risk management through storage and diversification (OECD, 2006).

There is a co-dependence between agricultural and economic growth and human development. A key strategy for poverty alleviation and agricultural development is the Integrated Sustainable Rural Development Strategy of South Africa. The intention of this strategy is to "transform rural South Africa into an economically viable and socially stable and harmonious sector that makes a significant contribution to the nation's GDP". The stated aim of the strategy is to benefit the rural poor generally, but in particular women, youths, and the disabled (RSA, 2000). Key to achieving the aims of this strategy is ensuring sufficient clean water for both domestic and agricultural demands. 


\section{Climate impacts affecting water availability}

An analysis of the rainfall trends for north western area of South Africa was made for the past 30 years (Mukheibir and Sparks, 2006). Unfortunately no clear trends could be observed for the annual rainfall figures since the data exhibited low correlation factors for the linear regression trend lines. However, what is significant is the high variability of the rainfall data from year to year, with periods of good rainfall followed by periods of drought. See Figure 5 which provides and illustration of this using rainfall data for Calvinia, located in this area. This variability results in unpredicted flooding and of importance in this study, drought. Unpredicted drought causes stress to vulnerable agriculture and small scale water resources. This makes planning for times of drought difficult yet essential.

Despite the wide range of uncertainty, there is an ever-increasing consensus amongst the scientific community that global climate change is a physical reality. Specifically for South Africa, temperature is expected to increase by approximately $1.5^{\circ}$ along the coast and $2^{\circ}-3^{\circ}$ inland of the coastal mountains by 2050 . Along with temperature increases, changes in evaporation, relative and specific humidity as well as soil moisture are anticipated (Midgley et al., 2005).

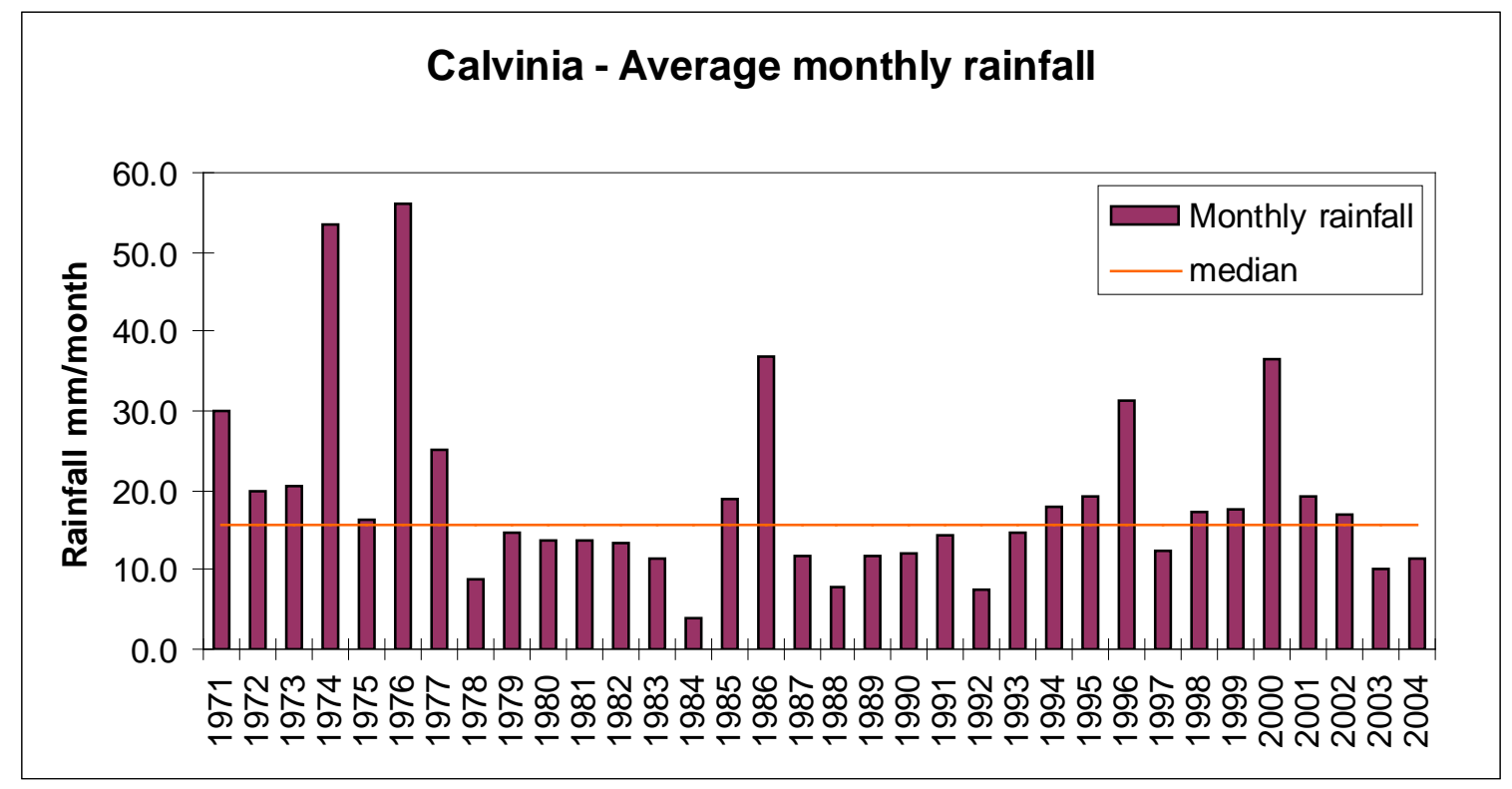

Figure 5: Annual average monthly rainfall trends for Calvinia between 1971 and 2004

Precipitation projections for southern Africa, as provided by empirical and regional climate model-based downscaling tools, indicate a wetter escarpment in the east, a shorter winter season in the southwest, a slight increase in intensity of precipitation, and drying in the far west (Hewitson et al., 2005). The climate change outputs from the models currently being used produced significantly different simulations, however, whilst there are still many uncertainties with regard to the magnitude, the direction of change appears to be consistent.

Hydrological responses are known to be sensitive to changes in rainfall. Runoff is highly sensitive to changes in precipitation and recharge is even more sensitive to changes in rainfall (Kiker, 2000). In drier areas where annual rainfall is less than $500 \mathrm{~mm}$, a $10 \%$ decrease in rainfall could translate into as much as a $40 \%$ decline in recharge (Cave et al., 2003). This has serious implications where rainfall is already low, and is predicted to decrease with projected future climate change and where groundwater is over-exploited at present.

As is illustrated in Figure 6, the production of agricultural products can be closely linked to the drought patterns of southern Africa. For example, there has been a steady increase in agricultural production since 1965. However, dips in production can be seen in the early 1970s, 1980s and mid 1990s, which correspond with the occurrence of significant droughts experienced in South Africa and serve to illustrate the vulnerability of agriculture to variations in climate, and potentially to long-term climate change. Using long-term records of past climate-recharge interactions is difficult to apply in southern Africa, since there are very few locations where records of climate and groundwater have been kept in sufficient detail to allow for this analysis (Selaolo et al., 2003). 


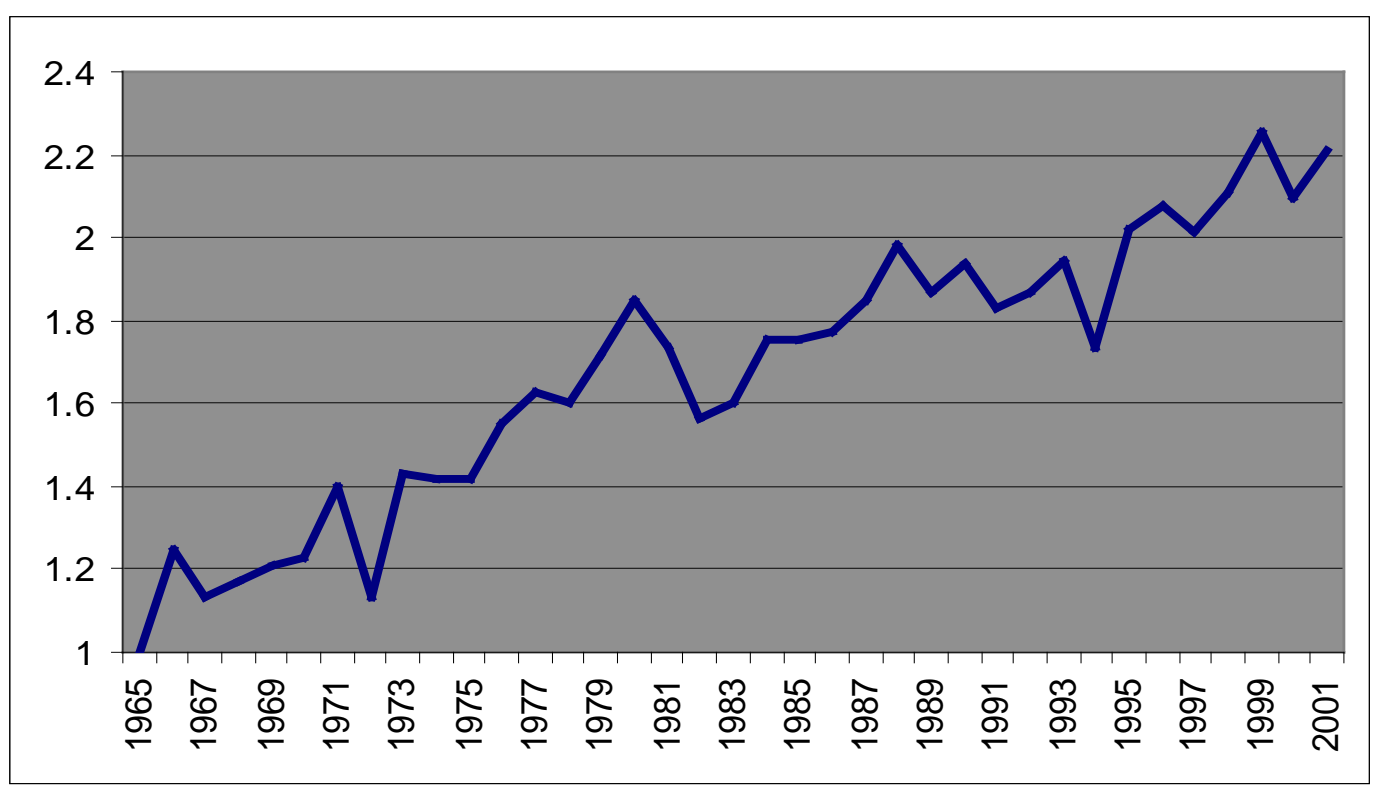

Figure 6. Indices of the volume of agricultural production measured against 1965 (NDA, 2002)

Crop yield modelling predicts that, under future climate scenarios, maize production will decrease by up to $20 \%$, mostly in the drier western regions. Speciality crops may also be at risk, since both rainfall and temperature effects may cause significant changes in areas uniquely suited for such specialised production (DEAT, 2004). However, research conducted by Abraha and Savage (2006) further showed that under increased carbon dioxide concentration regimes, maize yields are much more likely to be affected by changes in mean air temperature than by precipitation.

\section{Results: Viable strategies for future sustainable water supplies}

In the past governments responded to water scarcity by developing supply strategies. Large scale river diversions, as in the case of China and India, highlight the appeal of this option. For wealthier countries desalination and the importation of food from well watered regions to offset the water shortage in the local country ("virtual water") are options. Demand, driven by population growth and social upliftment, is initially met by supply-side management, even as the supply of water moves into one of water scarcity. However, when supply-side strategies fail to meet the demand needs, a second phase of water management, namely demandside management, comes into play. Hence a series of changes are needed within a social entity to meet the challenge of increase water scarcity (Turton, 1999).

Through a consultative process conducted in the Northern Cape with the Provincial Drought Forum, a selection of viable supply and demand side strategies was identified in terms of criteria listed in Table 1.

Table 1: Definitions of criteria for strategy analysis (Mukheibir, 2007)

\begin{tabular}{|l|l|}
\hline Additional yield / saving & $\begin{array}{l}\text { How will the intervention impact on water supply through additional } \\
\text { yield and/or savings? }\end{array}$ \\
\hline Technology required & Is the technology for the intervention readily available? \\
\hline Additional capital expenditure & Will the intervention require additional capital expenditure? \\
\hline Additional running costs & Will the intervention incur additional running costs? \\
\hline Local employment & To what extent will the intervention impact on job creation? \\
\hline Local capacity to implement & $\begin{array}{l}\text { What level is the institutional capacity currently at with respect to the } \\
\text { intervention? }\end{array}$ \\
\hline Acceptability to local community & $\begin{array}{l}\text { What is the consumer acceptability of this intervention in terms of } \\
\text { additional cost to them and convenience? }\end{array}$ \\
\hline
\end{tabular}




\begin{tabular}{|l|l|} 
Impact on local water resources & $\begin{array}{l}\text { What impact will the intervention have on the water resources and } \\
\text { the environment in the area? }\end{array}$ \\
\hline Long term applicability & What is the period of impact of the intervention? (short - long term) \\
\hline
\end{tabular}

It is important to attach weightings to the criteria since some will carry more significance than others. This exercise proved to be rather subjective, as can be seen in Figure 7, where different stakeholders ${ }^{2}$ placed lesser or greater importance on the different criteria, most notable is "local employment", where the local government officials and those from the Department of Agriculture placed a higher priority on this weight compared to the officials from the national Department of Water Affairs and Forestry. 'Acceptability to the local community' and 'capital expenditure' followed a similar trend.

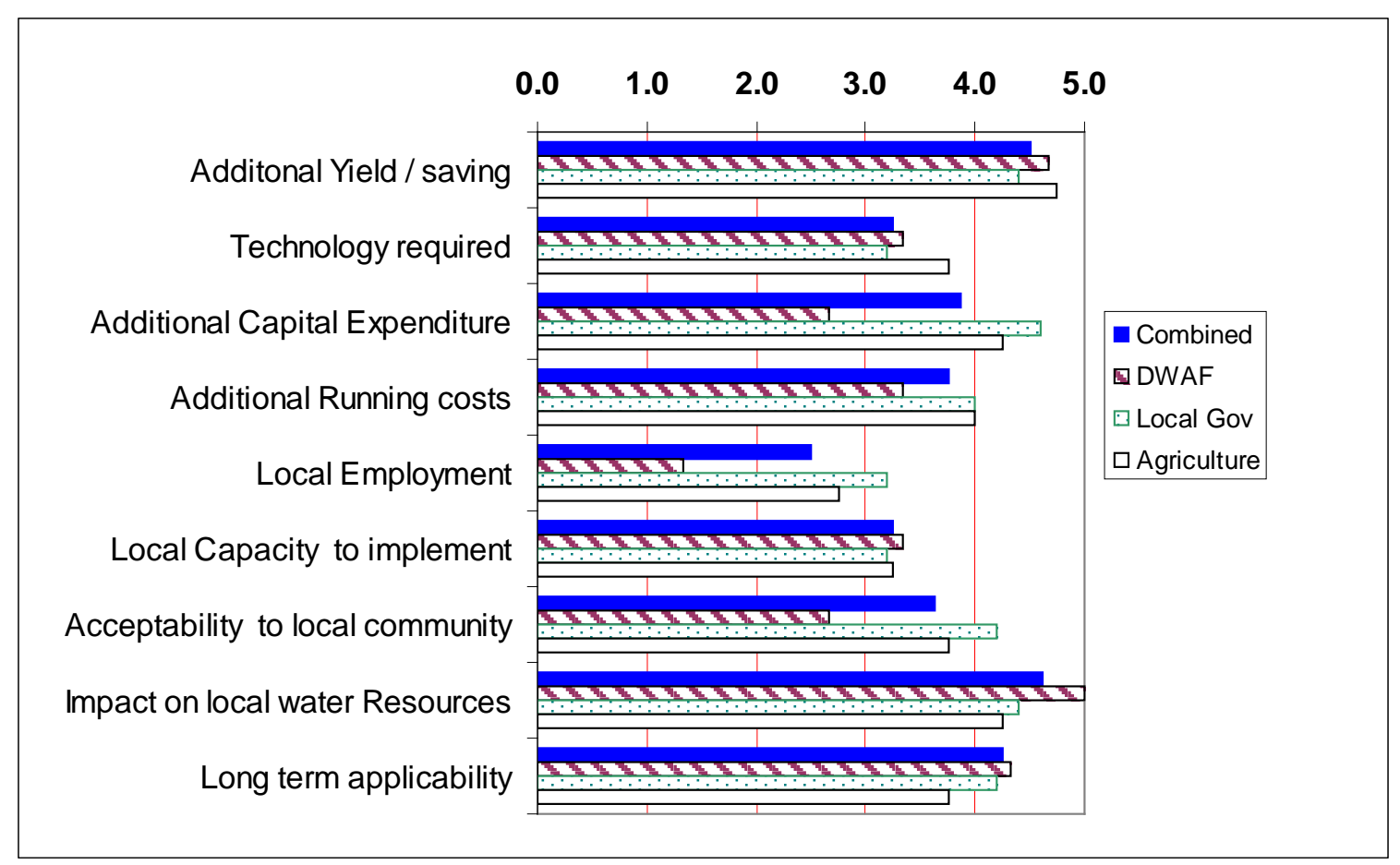

Figure 7: : Weighting of criteria by various stakeholders (Mukheibir and Sparks, 2006).

Strategies that did not meet these criteria include drought relief, standby relief, tankering of water, desalination, using saline water for toilets and rainfall enhancement. The following is a discussion of the various options and their potential for addressing climate change impacts.

\subsection{Supply side management strategies}

The conventional approach to water resources management has been to focus on increasing the supply. More recently this focus has shifted to reducing the amount of water demanded by the consumer. We first consider the supply options and in the next sub-section we discuss the demand side options selected by the stakeholders.

The optimisation of supply options requires sound planning and management of multiple sources of water and novel strategies such as groundwater recharge and rainwater harvesting. The reduction of leaks and the removal of alien vegetation reduces the water losses that could extend the life of existing supplies. Sound and reliable information systems provide timely warnings of droughts and allow for adequate planning. These strategy options are discussed further.

\footnotetext{
${ }^{2}$ Stakeholders drawn from the Northern Cape Drought Relief Forum, which is co-ordinated by the Department of Housing and Local Government, were requested to rank the list of strategies according to these criteria.
} 


\subsubsection{Planning and management}

\section{Water resources planning and management}

At a national level, DWAF has developed a National Water Resource Strategy (NWRS) to address the management of the water resources to meet the development goals of the country. One of the key objectives is to identify areas of the country where water resources are limited and constrain development as well as development opportunities where water resources are available. In addition, industrial users are required to develop and submit a water management plan if they draw their water directly from a water source (DWAF, 2004a).

Groundwater is likely to be most severely affected, with the groundwater table dropping due to reduced recharge, particularly in the western parts of the country. Strict groundwater management systems should be put in place with early warning mechanisms to report depleted groundwater reserves. The long term goal of DWAF is that local authorities manage their own water supply and demand. This can only be achieved if they are informed of the possible supply resources, monthly abstraction volumes and water quality and aquifer levels (Van Dyk et al., 2005).

As part of the planning and management of water resources, it has been suggested that each local authority be in a position to guarantee an assurance of water supply to its users under existing climatic conditions (Van Dyk et al., 2005). Approximately $25 \%$ of the towns in the Northern Cape were using more than $80 \%$ of their available groundwater resources during the drought of 2000. It is proposed that the peak demand should be $80 \%$ of the available yield of the resource. This would allow a buffer against drought and climate variability and would also allow the aquifer time to for recharge (Van Dyk, 2004).

\section{Conjunctive use of surface and groundwater}

To avoid the dependence on one source or type of source, some local authorities have made use of more than one type of water source, for example using both groundwater and surface water. This is most common where groundwater is found to be too saline for domestic use. One way to increase the available supply is to dilute the saline water with fresh water to acceptable concentrations. Alternatively, the saline water can also be used for flush toilets, whilst the treated water can be used for drinking and cooking. This type of system requires dual water supply and dedicated plumbing for each source, and hence could be costly to install. If identified at an early stage, the infrastructure can be installed in new developments to reduce the reticulation costs.

\section{Artificial groundwater recharge}

This is the process of transferring surface water into an aquifer, and could be in the form of rainfall run off, treated wastewater and urban storm runoff. Artificial recharge provides storage of local or imported surplus surface water for security during drought and dry seasons and can reverse the negative dewatering trend as well as improve the quality of the groundwater, specifically the salinity by replenishing the aquifer when river runoff is available.

A number of municipalities have demonstrated that this strategy is effective and applicable to both large scale schemes as well as small scale operations. It does require basic maintenance to ensure that the injection rate is optimised. Also, the quality of the water being injected needs to be of a high quality (Murray, 2004).

\subsubsection{Rainwater harvesting}

Whilst acknowledging the agricultural benefits of surface water harvesting, there are also benefit of improving the recharge of underground water, either by natural infiltration of the soil or by artificial recharge methods. The effectiveness of this does, however, depend on the aquifer type. In the southern tributary catchments of the Lower Orange water management area, the unique use of soil embankments has been employed as a means of rainwater harvesting (DWAF, 2004a). This practice enables additional recharging of the aquifer and reduces the runoff.

At a domestic level, rainwater harvesting from roofs is an effective way of augmenting drinking water, watering gardens and filling up swimming pools.

\subsubsection{Reduction of leaks}

In South Africa, the level of unaccounted for water in urban distribution systems is between 15 and $20 \%$, which is viewed as high by international standards (Goldblatt et al., 2002). Unaccounted for water not only amounts to losses in usable water, but also in potential revenue due to additional treatment and distribution costs. These losses are often passed onto the consumer, who are required to pay higher tariffs to offset these losses. Conveyance losses in the agricultural sector due the age of some schemes is also a major source of leakage losses.

With the stress on available water supplies, consumers cannot be expected to increase the available water resources through a reduction in demand alone. Losses in the system need to be addressed as part of supply 
management. Service providers should see this as one of their main target areas for "creating" more available water. It has been estimated that a saving of up to $15 \%$ of demand can be achieved by implementing effective distribution management measures, through initiatives such as proactive leak detection, the implementation of a leak repair and pipe replacement programme and the installation of pressure management systems that reduce the water pressure in pipelines at times of low usage (DWAF, 2004b).

\subsubsection{Control of invasive alien vegetation}

DWAF have initiated the 'Working for Water' programme to remove invasive alien invasive tree species from catchments in South Africa as part of local catchment management strategies and job creation programmes. Through the modification of the vegetation in various catchments, where water-thirsty vegetation with high transpiration rates has reduced the stream flow, the available water supply can be increased. Invading alien plants have covered about $8 \%$, of South Africa. They cause the loss of some $7 \%$ of the annual flow in South Africa's rivers each year - about 33 million $\mathrm{m}^{3}$ of water (This excludes the severe impact upon groundwater reserves). Through the Working for Water Programme, it is estimated that approximately 750000 hectares will need to be cleared each year over a 20-year period (Kasrils, 2000).

\subsubsection{Improved monitoring and forecasting systems for floods and drought}

It is possible that climate change will affect the frequency of floods and droughts. Monitoring systems will help in coping with these changes, even without the impact of climate change (Schulze and Perks, 2000). Planning for the most vulnerable water supply areas should be such that proper monitoring can provide early warning of problems including global change impacts.

Seasonal forecasts have been shown to be useful as an adaptive strategy to respond to climate variability, especially in determining the planting and harvesting times. The forecast information is currently available on an annual time step. However, there is still a need for improved support of seasonal forecast information at the national and district level (Ziervogel et al., 2005).

\subsection{Demand side management strategies}

It is calculated that the total opportunity in reducing water demand is approximately $39 \%$ of the total existing demand (DWAF, 2000). The implementation of urban and agricultural water demand management is a crucial intervention that must be implemented by all local authorities, so as to prolong the life of existing urban sources of supply. To encourage this at local level, DWAF have stated that they will not consider the licensing of new water resource developments for any local supply schemes unless water demand management has been implemented (Ninham Shand et al., 2004).

There are a number of ways to reduce the water demand by consumers. The first is to influence their consumption behaviour through punitive interventions such as water restriction and tariff structures. The second would be to provide incentives or assistance programmes which aim to reduce demand through for example changes in agricultural practices, low water use sanitation, recycling and on site leak reduction (White and Fane, 2002). This are discussed further.

\subsubsection{Water restrictions}

In some towns and cities water restrictions have been implemented as a means of curbing water demand (DHLG, 2005). This has been done either through rising block tariffs or the restriction of certain water uses, such as the watering of domestic gardens. In severe cases, users are restricted to a certain volume of water per day. Those exceeding this are fined.

Instituting water restrictions requires additional personnel capacity to police the interventions and to prosecute those who are offenders. The implementation of an education campaign to both inform users of the new measures and to make them aware of water saving practices also requires capacity and funding.

\subsubsection{Tariff structures}

One of the most effective ways being used by local authorities to encourage consumers to use water more efficiently is through tariff mechanisms. Market-based allocations are able to respond more rapidly to changing conditions of supply and also tend to lower the water demand, conserve water and consequently increase both the robustness and resilience of the water supply system (Schulze and Perks, 2000). In most cases a rising block tariff has been used to curb excessive use of water. This mechanism is designed along the principle of "the more you use the more you pay". This mechanism does not usually require additional staffing or resources, but an adjustment to the billing system. As can be seen from the example for Cape Town (Table 2), the local authority increased the water tariffs substantially in an attempt to curb excessive water use during the 2005 drought conditions. 
Table 2: Example of domestic consumption rising block tariff

(City of Cape Town, 2005)

\begin{tabular}{l|r|r|c}
\hline \hline \multirow{2}{*}{ Consumption in $k l$} & \multicolumn{3}{|c}{ Tariff per $k l$} \\
\cline { 2 - 4 } & $2004 / 5$ & $2005 / 6$ & increase \\
\hline $0-6$ & $\mathrm{R} 0.00$ & $\mathrm{R} 0.00$ & $\mathrm{R} 0.00$ \\
\hline $7-12$ & $\mathrm{R} 2.32$ & $\mathrm{R} 2.46$ & $6 \%$ \\
\hline $13-20$ & $\mathrm{R} 6.15$ & $\mathrm{R} 6.52$ & $6 \%$ \\
\hline $21-40$ & $\mathrm{R} 10.41$ & $\mathrm{R} 11.04$ & $6 \%$ \\
\hline $41-60$ & $\mathrm{R} 13.34$ & $\mathrm{R} 25.00$ & $87 \%$ \\
\hline $61+$ & $\mathrm{R} 17.20$ & $\mathrm{R} 50.00$ & $191 \%$ \\
\hline \hline
\end{tabular}

\subsubsection{Changes in agricultural management practices}

Adaptation strategies in the agricultural sector such as changes in crop types, planting dates, row spacing and planting density could be implemented to counter the effects of limited water. Practices such as conservation tilling, furrowing, terracing, contouring and planting vegetation as windbreaks, protect fields from water and wind erosion and assist in retaining moisture by reducing evaporation and increases infiltration (Abraha and Savage, 2006; DEAT, 2004).

lrrigation, which is widely used, will most likely become more expensive due to scarce water resources and higher fuel costs and this may need be phased out in favour of dry land farming. Currently losses through irrigation range between $30-40 \%$ of the demand, and is indicative of the potential for water demand management in the agricultural sector (DWAF, 2004c).

\subsubsection{Dry sanitation systems, low-flow systems and duel flush toilets}

According to Soroczan and Baynes (2003) toilets account for approximately $30 \%$ of total residential indoor water use. Some models of dual flush toilets use six litres of water to flush solid waste but only three litres of water to flush liquid waste. These toilets save an average of $26 \%$ more water over the single-flush six litre toilets. In places such as Australia and Singapore, this technology is mandatory.

In areas where there is a lack of water to allow conventional flush toilets, dry sanitation, pour flush and low flow systems should be considered. However, sometimes it is difficult to get buy-in from consumers in South Africa who have developmental aspirations for flush toilets. In areas that are dependent on groundwater, care must be taken to avoid contamination of groundwater source and composting latrines or lined chambers should be considered.

\subsubsection{Re-use of grey water}

Grey water utilisation at a domestic level can be beneficial for irrigating small gardens, and to lesser extent assisting in the recharge of groundwater resources. This practice not only reduces the water demand, but also relieves the volume on the waste water treatment works. Municipal byelaws are required to regulate this practice to avoid the contamination of the groundwater and to avoid the pooling of grey water, which could lead to the spread of diseases. The use of properly constructed French drains should be regulated.

\subsubsection{Leak reduction}

The average water wastage due to plumbing leaks in the household is estimated at $20 \%$ of the total indoor household water use (DWAF, 2004b). Consumers should be encouraged to maintain their internal reticulation systems and save on their water bills. Together with education programmes and pressure control systems, internal leaks can be reduced.

\subsubsection{Water education}

Public information and school education programs are key to highlighting the need and benefits of initiating water demand strategies. These programmes could include brochures, advertising, newsletters or magazine and newspaper inserts, exhibits and informative billing

\section{Discussion: Barriers to implementing adaptation}

In assessing the implementation potential of the strategies discussed, a number of obstacles and limitations to implementing these strategies have been identified. Specifically the issue of local human capacity and financial resources stood out as the most pressing (Mukheibir and Sparks, 2006). The former Director-General of 
DWAF, Mr Mike Muller, has stated that there is a severe shortage of qualified water managers in small to medium-sized municipalities which has resulted in $63 \%$ of municipalities not complying with the drinkingwater quality standards. There is an urgent need for formal training in this sector (Venter, 2005). This is further exacerbated by the low financial resource base to cover the capital and running costs of most of the strategies. Local government competes for nationally allocated funds for capital expenditure. Running costs are mostly covered from local revenues, which for the smaller and remote local municipalities, are insufficient to ensure water security at this level.

Political buy-in for some of the strategies such as water restrictions and dry sanitation will need to be obtained through education programmes, but these also require human and financial resources. It has been reported that in developing countries additional political and economic barriers result in little or no time and energy to address water savings. A shift in behaviour patterns is difficult irrespective of the level of education, wealth or size of the domestic unit. All water saving measures are not applicable to everyone, since their attitudes towards water differ (Yurdusev and Kumanhoglu, 2007).

Similar barriers to implementing water conservation and water demand management in the agricultural sector have been identified (DWAF, 2004c; Muller, 2007; OECD, 2006). Large financial investments as well as institutional and technical capacity are critical. Due to the transition from former lrrigation Boards to Water User Associations, there has been inadequate clarity on institutional arrangements, roles and responsibilities. There is also a general lack of technically qualified people to plan and implement water demand management measures.

There is little or no acknowledgement in the water or agricultural sector of projected climate change impacts. Education and awareness is greatly needed in this area.

\section{Conclusions}

Climate change does not feature prominently as a real threat to the reduction of the existing available water resources, so much so that strategies have not yet been developed to adapt to the projected impacts. Current water management mechanisms and policies have been developed to ensure that the existing supply of water meets the growing demand under current climate variability. However, robust long-term strategies are required to ensure the demand for water matches supply, even in times of reduced availability. The framework presented in this paper provides a tool with which to screen for viable long term strategies that also meet the local development goals.

These strategies require different resources such as financial and human, as well as the political support for the initiatives. Local and national government should look at policies and programmes that would address the low levels of financial and human resources at local government level. The integration and institutionalisation of adaptation with development activities, in the advent of climate change, should be seriously considered by planners in South Africa. It should not be an add-on or an after thought. Currently there is little evidence of this (Burton et al., 2002; Mukheibir and Ziervogel, 2007; Stern, 2006).

Long term strategies should be adopted that meet the local developmental needs and address the water resources management concerns. This will ensure that local governments have in place the necessary adaptive resilience to ensure that the communities they serve are assured adequate clean water to meet their developmental needs, despite the uncertainty of future climate projections.

\section{Acknowledgements:}

The research for this study was funded in part by the Water Research Commission of South Africa and Netherland Environmental Assessment Agency.

\section{References:}

Abraha MG, Savage MJ (2006) Potential impacts of climate change on the grain yield of maize for the midlands of KwaZulu-Natal, South Africa. Agriculture, Ecosystems and Environment, 115(1): 150-160.

Argrawala S (2005) Bridge over Troubled Waters: Linking Climate Change and Development. OECD, Paris, 154. 
Burton I, Huq S, Lim B, Pilifosova O, and Schipper EL (2002) From impacts assessment to adaptation priorities: the shaping of adaptation policy. Climate Policy, 2(2-3): 145-159.

Callaway JM (2004) Adaptation benefits and costs: are they important in the global policy picture and how can we estimate them? Global Environ Change, 14: 273-282.

Cave L, Beekman H, Weaver J (2003) Impact of Climate Change on Groundwater Recharge Estimation. Groundwater Recharge Estimation in Southern Africa, Y. Xu and H. Beekman, eds., UNESCO, Paris.

City of Cape Town (2005) Development and Infrastructure (Tariff funded) - Water Services - 20\% restriction tariff. http://www.capetown.gov.za/tariffs/.

Davidson O, Halsnaes K, Huq S, Kok M, Metz B, Sokona Y, Verhagen J (2003) The development and climate nexus: the case of sub-Saharan Africa. Climate Policy, 3(S1): S97-S113.

DEAT (Department of Environment and Tourism). (2004) A National Climate Change Response Strategy for South Africa. Pretoria.

DHLG (Department of Housing and Local Government). (2005) Provincial Drought Task Team Meeting minutes 13/01/2005. Kimberley.

DWAF (Department of Water Affairs and Forestry) (1994) Water supply and sanitation policy White Paper. Cape Town.

DWAF (Department of Water Affairs and Forestry) (1996) The Working for Water Programme annual report 1995/96. DWAF, Pretoria.

DWAF (Department of Water Affairs and Forestry) (1997) White paper on a National Water Policy for South Africa. DWAF.

DWAF (Department of Water Affairs and Forestry) (2000) DRAFT Water conservation and demand management strategy for the water services sector.

DWAF (Department of Water Affairs and Forestry) (2004a) National Water Resource Strategy. First Edition.

DWAF( Department of Water Affairs and Forestry) (2004b) Water conservation and demand management strategy for the water services sector.

DWAF (Department of Water Affairs and Forestry) (2004c) Water conservation and water demand management strategy for the agricultural sector.

Fischer G, van Velthuisen H, Shah M, Nachtergaele F (2002) Global agro-ecological assessment for agriculture in the 21st century. International Institute for Applied Systems Analysis, Austria.

Goldblatt M, Gelb S, Davies G. (2002) Macroeconomics and sustainable development in Southern Africa. Development Bank of Southern Africa.

Hewitson B, Tadross M, Jack C (2005) Scenarios from the University of Cape Town. Climate Change and Water Resources in Southern Africa: Studies on Scenarios, Impacts, Vulnerabilities and Adaptation, R. E. Schulze, ed., Water Research Commission., Pretoria, South Africa, 39 -56.

IPCC (International Panel on Climate Change). (2007) Summary for Policymakers: Climate Change 2007: Climate change impacts, adaptation and vulnerability., IPCC, Geneva.

Jeffrey P, Gearey M (2006) Integrated water resource management: lost on the road from ambition to realisation? Water Science and Technology, 53(1): 1-8.

Kasrils R (2000) A water perspective on invasive species. The best management practices symposium, Kirstenbosch.

Kiker GA (2000) Synthesis report for the vulnerability and adaptation assessment section: South African Country Study on Climate Change. Department of Environmental Affairs and Tourism, Pretoria.

Markandya A, Halsnaes K (2002) Climate change \& sustainable development: Prospects for developing countries. Earthscan, London.

Midgley GF, Chapman RA, Hewitson B, Johnston P, De Wit M, Ziervogel G, Mukheibir P, Van Niekerk L, Tadross M, Van Wilgen BW, Kgope B, Morant P, Theron A, Scholes RJ, 
Forsyth GG (2005) A Status Quo, Vulnerability and Adaptation Assessment of the Physical and Socio-Economic Effects of Climate Change in the Western Cape, Report to the Western Cape Government, Cape Town, South Africa. Report No. ENV-S-C 2005-073, CSIR, Stellenbosch.

Mosdell T, Leatt A (2005) On Tap: A review of the Free Basic Water Policy. Towards a Means to Live: Targeting poverty alleviation to make children's rights real, A. Leatt and S. Rosa, eds., Children's Institute, University of Cape Town, Cape Town.

Mukheibir P (2007) Qualitative assessment of municipal water resource management strategies under climate impacts: the case of the Northern Cape, South Africa. Water SA, 33(4): 575581.

Mukheibir P, Sparks D (2006) Climate variability, climate change and water resource strategies for small municipalities. WRC Report No. 1500/1/06, Water Research Commission, Pretoria, South Africa.

Mukheibir P, Ziervogel G (2007) Developing a Municipal Adaptation Plan (MAP) for climate change: the city of Cape Town. Environment \& Urbanisation, 19(1): 143-158.

Muller M (2007) Adapting to climate change: water management for urban resilience. Environment \& Urbanisation, 19(1): 99-114.

Munasinghe M, Swart R (2005) Primer on climate change and sustainable development: Facts, policy analysis and applications, Cambridge University Press, Cambridge.

Murray EC (2004) Wise water management for towns and cities - Artificial groundwater recharge. Report No TT219/03, Water Research Commission, Pretoria.

NDA (2002) Abstract of agricultural statistics. Pretoria.

Ninham Shand, Asch Consulting Engineers, Jackoet \& Associates (2004) Clanwilliam Dam Raising Study Specialist Screening Workshop. Workshop starter document.

OECD (2006) Agricultural Policy Reform in South Africa. Policy Brief, Pretoria.

Otieno FAO, Ochieng GMM (2004) Water management tools as a means of averting a possible water scarcity in South Africa by the year 2025. Water SA, 30(5): 668 - 672.

Reid P, Massay R, Vogel C (2005) Climate and development: Experiences of farmers in Kwa-ZuluNatal, South Africa In: Schulze, R.E. (Ed) Climate Change and Water Resources in Southern Africa: Studies on Scenarios, Impacts, Vulnerabilities and Adaptation. Water Research Commission, Pretoria, Chapter 25, pp 395 - 414.

Reid P, Vogel C (2006) Living and responding to multiple stressors in South Africa - Glimpses from KwaZulu-Natal. Global Environmental Change, 16(2): 195-206.

RSA (Republic of South Africa). (2000) Integrated Sustainable Rural Development Strategy (ISRDS). Pretoria.

Schulze R, Perks L (2000) Assessment of the Impact of Climate Change on Hydrology and Water Resources in South Africa. ACRUcons Report 33, School of Bioresources Engineering and Environmental Hydrology, University of Natal, Pietermaritzburg.

Selaolo ET, Beekman H, Gieske ASM, De Vries JJ (2003) Multiple tracer profiling in Botswana. Groundwater Recharge Estimation in Southern Africa, Y. Xu and H. Beekman, eds., UNESCO, Paris.

Soroczan C, Baynes S (2003) Dual-flush Toilet Testing. Canadian Mortgage Housing Corporation.

SSA (2003) Key results: Census 2001. Pretoria.

Stern N (2006) Stern Review: The economics of climate change. HM Treasury, London.

Turton A (1999) Water Scarcity And Social Adaptive Capacity: Towards An Understanding Of The Social Dynamics Of Water Demand Management In Developing Countries. Water Issues Study Group, School of Oriental and African Studies, University of London.

Van Dyk G (2004) Geohydrology, DWAF Northern Cape.

Van Dyk G, Peters R, Fourie S (2005) Water provision from Groundwater in the Northern Cape: Balancing demand and supply. Biennial Groundwater Conference, 381 -391. 
Venter I (2005) Back to basics. Engineering News.

White SB, Fane SA (2002) Designing cost Effective Water Demand Management Programmes in Australia. Water Science and Technology, 46(6-7): 225-232.

WHO (1995) Community Water Supply and Sanitation: Needs, Challenges and Health Objectives. 48th World Health Assembly A48/INF.DOC./2, 28, World Health Organization.

Yurdusev MA, Kumanhoglu, AA (2007) Survey-based estimation of domestic water saving potential in the case of Manisa City. Water Resources Management, on line.

Ziervogel G, Bharwani S, Downing T (2005) Adapting to climate variability: Pumpkins, people and policy. Natural Resources Forum, 30(4). 